\title{
PERENCANAAN DAN PENGONTROLAN PERSEDIAAN MINYAK CANGKANG SEBAGAI SUMBER ENERGI ALTERNATIF (Studi Kasus: PT. Agro Masang Perkasa Plantation)
}

\author{
Abdul Latif ${ }^{1}$ dan Afifah Fauzi ${ }^{2}$ \\ 1,2 Jurusan Teknik Industri Sekolah Tinggi Teknologi Industri \\ email:abdullatief@sttind.ac.id
}

\begin{abstract}
Abstrak:Kelapa sawit adalah salah satu produk pertanian terpenting di Indonesia. Saat ini sudah banyak perusahaan yang bergerak di bidang sawit, salah satunya adalah PT. Agra Masang Perkasa (AMP) Plantation. PT. AMP Plantation memproduksi Cruid Palm Oil (CPO) dan kernel dengan kapasitas produksi \pm 80 ton / jam dan 200 ton / hari. Proses produksi membutuhkan bahan bakar untuk pabrik mesin diesel. Untuk mengurangi ketergantungan perusahaan pada sumber energi konvensional, cangkang digunakan sebagai bahan bakar alternatif. Untuk mencegah kekurangan persediaan cangkang, perusahaan harus melakukan kontrol atas pasokan cangkang secara terus menerus dan teratur. Tujuan penelitian ini adalah untuk menentukan jumlah produksi dan pasokan cangkang sawit di PT. AMP Plantation. Prediksi produksi cangkang dilakukan dengan menggunakan metode peramalan yang terdiri dari metode trend linear, quadratic dan exponential trend. Metode peramalan dengan exponential trend memiliki kesalahan persentase terkecil sehingga pengolahan dapat terus dilakukan dengan metode Economic Product Quantity (EPQ). Dari perhitungan yang telah dilakukan diperoleh jumlah produksi cangkang yang optimal yaitu $4.607 .171 \mathrm{~kg} /$ tahun dengan ratarata produksi $383.931 \mathrm{~kg} /$ bulan, sedangkan biaya persediaan produksi cangkang optimal 1.485.695.895 / tahun.
\end{abstract}

Kata kunci: cangkang, peramalan, EPQ, produksi, biaya

Abstract: Palm oil is one of the most important agricultural products in Indonesia. Currently there are many companies engaged in the oil palm sector, one of which is PT. Agra Masang Perkasa (AMP) Plantation. PT. AMP Plantation produces Crude Palm Oil (CPO) and kernels with a production capacity of \pm 80 tons/hour and 200 tons/day. The production process requires fuel for diesel engine factories. To reduce the company's dependence on conventional energy sources, shells are used as alternative fuels. To prevent a shortage of shell supplies, companies must control the supply of shells continuously and regularly. The purpose of this study was to determine the amount of production and supply of palm shells at PT. AMP Plantation. Shell production prediction is carried out using a forecasting method consisting of a linear, quadratic and exponential trend method. Forecasting method with exponential trend has the smallest percentage error so that processing can continue to be carried out using the Economic Product Quantity (EPQ) method. From the calculations that have been carried out, the optimal amount of shell production is 4,607,171 kg/year with an average production of $383,931 \mathrm{~kg} / \mathrm{month}$, while the optimal cost of producing shell production is 1,485,695,895/year.

Keywords: shell, forecasting, EPQ, production, costs

\section{PENDAHULUAN}

Kelapa sawit merupakan salah satu hasil pertanian yang terpenting di Indonesia. Berdasarkan data Ditjen Perkebunan Kementerian Pertanian diketahui luas area lahan kelapa sawit di Indonesia pada tahun 2012 mencapai 9.271.000 hektar. Walaupun kelapa sawit bukan tanaman asli Indonesia tetapi produknya yang berupa minyak kelapa sawit telah menjadi salah satu komuniti perkebunan yang handal. Saat ini telah banyak perusahaan-perusahaan yang bergerak diperkebunan kelapa sawit salah satu nya PT.Agra Masang Perkasa (AMP) Plantation. 
PT Agra Masang Perkasa (AMP) Plantation beralamat di Jln. Lintas Manggopoh, Simpang IV Pasaman, Desa Tapian Kandis Kenagarian Salareh Aia, Kecamatan Palembayan, Kabupaten Agam, Sumatera Barat. Luas Pabrik Pengolahan Kelapa Sawit (PKS) \pm $200.900 \mathrm{M}^{2}$ (SK Bupati Agam Nomor: 125/IMB/BA/1994 tertanggal 22 Desember 1994 dan Nomor:11/IMB/2005 Tanggal 13 September 2005).

PT. AMP Plantation memproduksi Cruid Palm Oil (CPO) dan kernel dengan kapasitas produksi \pm 80 ton /jam dan 200 ton/hari, dalam proses produksinya membutuhkan bahan bakar untuk mesin diesel pabrik. Untuk mengurangi ketergantungan perusahaan terhadap sumber-sumber energi konvensional (BBM) yang berkali-kali mengalami kenaikan harga sangat membebani operasional perusahaan, sehingga cangkang dijadikan sebagai bahan bakar alternatif. Perbandingan penggunaan energi antara batubara, cangkang dan solar untuk bahan bakar mesin diesel pabrik PT. AMP adalah sebesar 25,13\%, 27,24\% dan 47,62 \%. Hal ini mampu meminimalkan total cost yang harus dikeluarkan perusahaan, karena pasokan bahan bakar cangkang ini sebagian besar berasal dari pengolahan kelapa sawit hasil perkebunan milik perusahaan.

Untuk mencegah terjadinya kekurangan persediaan cangkang, perusahaan harus melakukan pengendalian terhadap persediaan cangkang secara terus menerus dan teratur. Tujuannya, agar persediaan cangkang dapat memenuhi kebutuhan untuk produksi sehingga peningkatan biaya sebesar 20-30\% per produksi dapat dihindari. Metode yang digunakan untuk pengendalian ketersediaan stok cangkang adalah metode Economic Production Quantity (EPQ). Metode $E P Q$ dapat menggambarkan jumlah persediaan cangkang yang dibutuhkan perusahaan untuk berproduksi. Metode ini dinilai mampu memberikan solusi yang terbaik bagi perusahaan, tidak saja diketahui berapa jumlah persediaan cangkang yang dibutuhkan perusahaan tetapi akan diketahui juga biaya yang akan dikeluarkan dengan persediaan yang dimiliki.

Tujuan penelitian adalah untuk mengetahui jumlah produksi cangkang kelapa sawit yang optimal di PT.AMP Plantation dan total biaya persediaan untuk produksi cangkang kelapa sawit yang optimal di PT.AMP Plantation.

\section{METODE PENELITIAN}

Jenis penelitian ini adalah penelitian deskriptif kuantitatif. Penelitian kuantitatif mengacu pada strategi penelitian, seperti observasi terhadap aktivitas dari subyek yang diteliti, kerja lapangan dan sebagainya, yang memungkinkan penelitian memperoleh informasi dari tangan pertama mengenai permasalahan empiris yang hendak digali, sehingga berbagai gejala yang timbul dari objek penelitian dapat dirumuskan secara objektif dan rasional serta sistematis. Jenis penelitian kualitatif dapat memberi rincian yang kompleks tentang suatu fenomena. Penelitian kualitatif yaitu penelitian yang bermaksud untuk memahami fenomena tentang apa yang dialami oleh subyek penelitian dan dengan cara deskripsi dalam bentuk kata-kata dan bahasa pada suatu konteks khusus yang alamiah dan dengan memanfaatkan berbagai metode alamiah.

Adapun jenis pendekatan penelitian kualitatif yang digunakan adalah studi kasus (case study). Case Study adalah metode yang secara sistematis menggali informasi tentang seseorang/institusi, setting sosial, peristiwa atau kelompok yang memungkinkan peneliti untuk mengerti bagaimana proses tersebut berlangsung dan berfungsi. Peneliti memotret penggunaan dan efektifitas metode EPQ dalam pengendalian persediaan bahan bakar cangkang sawit sebagai sumber energi alternatif di PT. Agro Masang Perkasa (AMP) Plantation ini secara lebih rinci dan kompleks dan dideskripsikan secara jelas serta faktual 
sesuai dengan data-data yang diperoleh di lapangan.

Data sekunder adalah sumber data yang tidak lansung memberikan data kepada pengumpul data. Pada penelitian ini data yang dibutuhkan yaitu data biaya, biaya penyimpanan, jumlah produksi dan jumlah penyaluran. Data penelitian ini bersumber dari PT. Agro Masang Perkasa (AMP) Plantation dan data-data lain yang bersumber dari perpustakaan yang bertujuan untuk melengkapi keperluan analisa terhadap data sekunder yang dikumpulkan.

\section{HASIL DAN PEMBAHASAN}

PT Agra Masang Perkasa (AMP) Platation Perusahaan ini bergerak dibidang usaha sektor perkebunan dan industri kelapa sawit, total luas areal tanaman sesuai dengan kondisi saat ini luas kebun : $\pm 12.642,78$ Ha yang terdiri dari kebun inti dan kebun plasma. Luas kebun inti : $\pm 9.226,42 \mathrm{Ha}$ dan luas kebun plasma : $\pm 3.416,36$ Ha. Luas Pabrik Pengolahan Kelapa Sawit (PKS) \pm 200.900 M2 (SK Bupati Agam Nomor: 125/IMB/BA/1994 tertanggal 22 Desember 1994 dan Nomor:11/IMB/2005 Tanggal 13 September 2005). Berdasarkan Laporan Manajemen Bulanan (LMB) PT. AMP Plantation diperoleh data biaya pengadaan dan penyimpanan untuk cangkang PT. AMP Plantation sebagai berikut :

Tabel 1. Biaya Pengadaan dan Penyimpanan Cangkang

\begin{tabular}{|c|c|c|}
\hline Tahun & $\begin{array}{c}\text { Biaya } \\
\text { Pengadaan } \\
(\mathrm{Rp})\end{array}$ & $\begin{array}{c}\text { Biaya } \\
\text { Penyimpanan } \\
(\mathrm{Rp})\end{array}$ \\
\hline 2012 & 4.313 .927 .917 & 931.942 \\
\hline 2013 & 4.939 .022 .565 & 1.116 .536 \\
\hline 2014 & 4.950 .054 .563 & 1.105 .788 \\
\hline
\end{tabular}

Sumber: Laporan Manajemen Bulanan (LMB) PT. AMP Plantation

Dari data biaya pengadaan dan penyimpanan, serta dari data jumlah produksi dan penyaluran cangkang kelapa sawit yang terhitung dari September 2013 sampai dengan Agustus 2014 dapat digunakan untuk menggambarkan penerapan dan efektifitas metode EPQ dalam mengendalikan persediaan cangkang untuk proses produksi PT.AMP Plantation. Data-data ini akan diolah menggunakan model EPQ untuk memperoleh jumlah produksi optimal, interval waktu optimal dan biaya minimum persediaan untuk tiap putaran produksi.

\section{Prediksi Jumlah Produksi Cangkang}

Sebelum melakukan perhitungan EPQ terlebih dahulu dilakukan peramalan produksi cangkang untuk periode yang akan datang. Hal ini dilakukan karena data produksi cangkang yang ada sekarang jika dilanjutkan pengolahannya maka hasilnya akan mubazir. Untuk itu penulis melakukan perhitungan peramalan produksi cangkang selama 12 bulan yang akan datang dari september 2014 Agustus 2015. Adapun metode yang digunakan adalah :

\section{Metode Trend Linear}

Perhitungan peramalan produksi cangkang dengan metode Trend Linear adalah sebagai berikut :

Tabel 2. Hasil Peramalan Produksi Cangkang Dengan Metode Trend Linear

\begin{tabular}{|l|l|l|l|}
\hline No & Periode (n) & Prediksi (x) & Produksi $\left(\mathrm{y}^{\prime}\right) \mathrm{kg}$ \\
\hline 1 & September (2014) & 13 & 410.212 \\
\hline 2 & Oktober (2014) & 15 & 404.694 \\
\hline 3 & November (2014) & 17 & 399.176 \\
\hline 4 & Desember (2014) & 19 & 393.658 \\
\hline 5 & Januari (2015) & 21 & 388.139 \\
\hline 6 & Februari (2015) & 23 & 382.621 \\
\hline 7 & Maret (2015) & 25 & 377.103 \\
\hline 8 & April (2015) & 27 & 371.585 \\
\hline 9 & Mei (2015) & 29 & 366.066 \\
\hline 10 & Juni (2015) & 31 & 360.548 \\
\hline 11 & Juli (2015) & 33 & 355.030 \\
\hline 12 & Agustus (2015) & 35 & 349.512 \\
\hline & Jumlah & & 4.558 .344 \\
\hline
\end{tabular}

Hitung standar error dengan menggunakan metode Persentase Error (PE)

$$
\begin{aligned}
\mathrm{PE}= & \left(\left(\mathrm{y}-\mathrm{y}^{\prime}\right) / \mathrm{y}\right) .100 \% \\
\mathrm{PE}= & ((5.352 .968-4.558 .344) / 5.352 .968) \\
& .100 \%=14,24 \%
\end{aligned}
$$




\section{Metode Trend Kuadratik}

Perhitungan peramalan produksi cangkang dengan metode Trend Kuadratik adalah sebagai berikut :

Tabel 3. Hasil Peramalan Produksi Cangkang Dengan Metode Trend Kuadratik

\begin{tabular}{|l|l|l|l|}
\hline No & Periode (n) & $\begin{array}{l}\text { Prediksi } \\
(\mathrm{x})\end{array}$ & $\begin{array}{l}\text { Produksi } \\
\left(\mathrm{y}^{\prime}\right) \mathrm{kg}\end{array}$ \\
\hline 1 & September (2014) & 13 & 371.600 \\
\hline 2 & Oktober (2014) & 15 & 543.084 \\
\hline 3 & November (2014) & 17 & 740.000 \\
\hline 4 & Desember (2014) & 19 & 960.000 \\
\hline 5 & Januari (2015) & 21 & 1.200 .000 \\
\hline 6 & Februari (2015) & 23 & 1.474 .080 \\
\hline 7 & Maret (2015) & 25 & 1.768 .070 \\
\hline 8 & April (2015) & 27 & 2.088 .657 \\
\hline 9 & Mei (2015) & 29 & 2.429 .570 \\
\hline 10 & Juni (2015) & 31 & 2.797 .060 \\
\hline 11 & Juli (2015) & 33 & 3.189 .060 \\
\hline 12 & Agustus (2015) & 35 & 3.605 .560 \\
\hline & Jumlah & & 21.166 .741 \\
\hline
\end{tabular}

\section{Metode Trend Eksponensial}

Perhitungan peramalan produksi cangkang dengan metode trend eksponensial

Tabel 4. Hasil Peramalan Produksi Cangkang Dengan Metode Trend Eksponensial

\begin{tabular}{|l|l|l|l|}
\hline No & Periode (n) & $\begin{array}{l}\text { Prediksi } \\
(\mathrm{x})\end{array}$ & Produksi (y') kg \\
\hline 1 & $\begin{array}{l}\text { September } \\
(2014)\end{array}$ & 13 & 408.139 \\
\hline 2 & Oktober (2014) & 15 & 403.557 \\
\hline 3 & $\begin{array}{l}\text { November } \\
(2014)\end{array}$ & 17 & 397.605 \\
\hline 4 & $\begin{array}{l}\text { Desember } \\
(2014)\end{array}$ & 19 & 394.660 \\
\hline 5 & Januari (2015) & 21 & 390.270 \\
\hline 6 & Februari (2015) & 23 & 385.925 \\
\hline 7 & Maret (2015) & 25 & 381.632 \\
\hline 8 & April (2015) & 27 & 377.383 \\
\hline 9 & Mei (2015) & 29 & 373.183 \\
\hline 10 & Juni (2015) & 31 & 369.030 \\
\hline 11 & Juli (2015) & 33 & 364.926 \\
\hline 12 & Agustus (2015) & 35 & 360.862 \\
\hline & Jumlah & & 4.607 .171 \\
\hline
\end{tabular}

\section{Menghitung Jumlah Produksi Optimal September 2014 - Agustus 2015}

Berdasarkan data prediksi jumlah produksi cangkang PT. AMP Plantation dapat diketahui jumlah produksi sebesar $4.607 .171 \mathrm{~kg}$ sehingga dapat dihitung ratarata produksi $(\mathrm{P})$ sebesar :

$\mathrm{P}=4.607 .171 / 12=383.931 \mathrm{~kg} / \mathrm{bulan}$

Selain itu juga diperoleh data penyaluran sebesar $2.314 .016 \mathrm{~kg}$ sehingga dapat dihitung rata-rata penyaluran ( D) sebesar :

$\mathrm{D}=2.314 .016 / 12=192.835 \mathrm{~kg} / \mathrm{bulan}$.

Laporan Manajemen Bulanan (LMB) PT. AMP Plantation menunjukan bahwa biaya pengadaan bahan bakar dan penyimpanan cangkang pada tahun 2014 adalah Rp. 4.950.054.563 dan Rp. 1.105.788, sehingga dapat dihitung biaya pengadaan $(\mathrm{Cs})$ dan penyimpanan $(\mathrm{Cc})$ produksi sebesar :

$\mathrm{Cs}=4.950 .054 .563 / 12=$

Rp. 412.504.547/bulan

$\mathrm{Cc}=1.105 .788 / 12 \quad=$

Rp. 92.149/bulan

Selanjutnya dari penghitungan diatas dapat diperoleh jumlah produksi optimal (Qo) dengan perhitungan metode EPQ sebagai berikut :

$$
\begin{aligned}
& \text { Qo }=2(192.834,667)(412.504 .547) \\
& (1-\quad 192.835 / 383.931)(92.149) \\
& =58.894,824 \mathrm{~kg} / \text { bulan }
\end{aligned}
$$

\section{Menghitung Interval Waktu Optimal}

Berdasarkan hasil penghitungan jumlah produksi optimal (Qo) sebesar $58.894,824 \mathrm{~kg} /$ bulan dan rata-rata penyaluran (D) sebesar $192.835 \mathrm{~kg} / \mathrm{bulan}$, sehingga kemudian dapat dihitung interval waktu optimal (to) sebagai berikut:

to $=58.894,824 / 192.834,667=0,305416$ bulan

Maka interval waktu optimal pada setiap putaran produksi adalah 0,305416 bulan. Artinya setiap 0,305416 bulan dilakukan proses produksi bila diasumsikan 1 bulan 30 hari maka interval waktu nya adalah : 9.16248 hari.

\section{Menghitung Biaya Minimum Persediaan}

Berdasarkan hasil perhitungan jumlah produksi optimal dalam (Qo) yang disubstitusikan terhadap $Q$ sehingga kemudian dapat dihitung biaya minimum persediaan (Tco) sebagai berikut : 
$\mathrm{Tco}=192.835 / 58.894,824.412 .504 .547$ +( (1-192.835/ 383.931) . 58.894,824/ 2 . $92.149=$ Rp. $1.485 .695 .895 /$ tahun

Dari hasil penghitungan tersebut diperoleh biaya minimum untuk setiap kali produksi adalah Rp. 1.485.695.895/ tahun . 0,305416 bulan $=$ Rp. 453.755 .297

\section{KESIMPULAN}

Berdasarkan hasil penelitian yang telah dilakukan maka dapat diambil beberapa kesimpulan sebagai berikut :

1. Jumlah produksi cangkang kelapa sawit yang optimal untuk setiap kali proses produksi di PT.AMP Plantation adalah $383.931 \mathrm{~kg} /$ bulan.

2. Jumlah biaya persediaan optimal agar tercapai efesiensi biaya produksi cangkang kelapa sawit di PT.AMP Plantation adalah Rp. 1.485.695.895/ tahun

\section{DAFTAR PUSTAKA}

Assauri, Sofjan. 2004. Perencanaan Pengendalian dan Pengawasan Produksi. Jakarta.

Ahyari, Agus. 2003. Manajemen dan Pengendalian Produksi. BPFE. Yogyakarta.

Bambang Riyanto. 2001. Dasar-Dasar Pembelanjaan Perusahaan. BPFE. Yogyakarta.

Baroto, Teguh. 2002. Perencanaan dan Pengendalian Produksi. Galia Indonesia. Jakarta

Jhon, DT dan Harding H.A. 2001. Manajemen Produksi ${ }^{2 n d}$ Edition. Balai Aksara. Jakarta.

Martin and Pretty. 1996.Production Planning Control and Integratio. Mc Graw - Hill. USA.

Prawirosentono, Suyadi. 2001.Teknik Peramalan. Rineka Cipta. Jakarta.

Rangkuty, Freddy. 2004. Manajemen persediaan Aplikasi di Bidang Bisnis. Raja Grafindo Persada. Jakarta.

Syahputra, Rija. 2012. Pengertian Variabel dan Jenisnya. Jakarta

Sugiono. 2010. Teknik Pengolahan Data. Jakarta
Zulfikarijah, Fien. 2004. Operation Research. Bayu Media Publishing. Malang. 